\title{
Knowledge and Practices of Colorectal Cancer Early Detection Examinations in Jordan: A Cross Sectional Study
}

\author{
Hana Taha ${ }^{1,2 *}$, Madi Al Jaghbeer ${ }^{1}$, Mohammed Qussay Al-Sabbagh ${ }^{1}$, Lujain Al \\ Omari $^{1}$, Vanja Berggren ${ }^{2,3}$
}

\begin{abstract}
Background: Globally, colorectal cancer $(\mathrm{CRC})$ is ranked the third most common cancer among men and the second in women. The American Cancer Society recommends that starting from the age 50 years, both men and women should be screened for polyps and for early detection of CRC. In Jordan, CRC is the most common cancer among males and the second most common cancer among females. This study aims to assess the knowledge and practices of CRC early detection tests and the barriers and motivators of screening in Jordan. Methods: A semi-structured questionnaire and face-to-face interviews were conducted with 300 males and 300 females recruited using stratified clustered random sampling technique from four governorates in Jordan. The participants were aged 30 to 65 years, without a previous history of CRC. Descriptive and multivariate analyses were used to assess knowledge and practices of CRC early detection tests. Results: Overall, there were poor knowledge and practices of CRC early detection tests. Better knowledge and practices were significantly associated with previously consulting a doctor due to symptoms and worries from $\mathrm{CRC}$, receiving a recommendation from a doctor to perform CRC testing, or having more knowledge about CRC signs and symptoms $(\mathrm{p} \leq$ 0.05). Conclusions: This study indicates that there is a need for raising awareness about CRC early detection tests in Jordan, especially among those aged 50 years and above, and those who have a family history of $\mathrm{CRC}$. Additionally, it is important to educate and encourage physicians to recommend CRC screening to patients that are at higher risk of the disease.
\end{abstract}

Keywords: Colorectal cancer- early detection tests- knowledge- practices- Jordan

Asian Pac J Cancer Prev, 20 (3), 831-838

\section{Introduction}

\section{Background}

Globally, colorectal cancer (CRC) is the third most common cancer among men and the second in women (10\% and $9.2 \%$ of the total cancer incidence in 2012 , respectively), (Ferlay et al., 2015). In 2012, around 1.4 million new cases of CRC were diagnosed worldwide (Ferlay J; Bray et al., 2013; Ferlay et al., 2015). Approximately $55 \%$ of these cases occurred in more developed countries. CRC is the fourth most common cause of cancer mortality globally, following lung, liver and stomach cancer. In 2012, there were 694,000 deaths due to CRC in both sexes with more deaths (52\%) occurring in less developed regions of the world which indicates poorer prognosis in these countries.

Based on the data from the American Cancer Society (ACS, 2018); there is no proven way to prevent colorectal cancer. However, there are modifiable risk factors that can be controlled to minimize the risk of developing the disease.
Additionally, The ACS recommends that starting at age 50 , both men and women, should perform the following screening tests as the first choice to find both polyps and early CRC: Colonoscopy every 10 years, Computed tomography colonography (virtual colonoscopy) every 5 years, Flexible sigmoidoscopy every 5 years, or Double-contrast barium enema every 5 years. If not possible, the ACS recommends the following tests that can mostly find CRC: annual Fecal Immunochemical Test (FIT), annual Fecal Occult Blood Test (FOBT), or Stool DNA Test every 3 years. If any of these tests is positive, a colonoscopy should be done.

Mortality due to cancer in Jordan is ranked second after cardiovascular diseases (Jordan Ministry of Health, 2012). $\mathrm{CRC}$ is the second most common cancer overall in Jordan. In 2012, there were 567 new CRC cases, which accounted for $11.3 \%$ of all the newly diagnosed cancer cases in the country. It is the highest ranking cancer among males (282 new cases, $12 \%$ of all male cancers) and the second most common cancer among females

${ }^{1}$ Department of Family and Community Medicine, School of Medicine, The University of Jordan, Amman, Jordan, ${ }^{2}$ Faculty of Medicine, Lund University, Lund, ${ }^{3}$ Department of Neuroscience, Caring Science and Society, Karolinska Institutet, Stockholm, Sweden. *For Correspondence: hanagh@yahoo.com 
( 285 new cases, $10.7 \%$ of all female cancers). The median age at diagnosis of colon cancer was 63 years in males and 60 for females. While the median age at diagnosis for rectal cancer was 58 years in males and 60 in females.

In 2012, there were 212 deaths due to CRC, which constituted $12.4 \%$ of all cancer deaths in the country. The national cancer registry data (Jordan Ministry of Health, 2012) indicated that the majority of CRC cases were adenocarcinomas $(81 \%)$, with rectal cancer being the most common site $(22.6 \%)$, followed by sigmoid colon $(21.7 \%)$ recto-sigmoid $(9.9 \%)$, cecum $(7.9 \%)$ and unknown sites in the colon was $(12.3 \%)$. Approximately $27.7 \%$ of cases were diagnosed as localized, $27 \%$ were in the regional stage, $21.2 \%$ has already metastasized, $22 \%$ as unknown. The five and ten-year survival rates for CRC were $58.2 \%$ and $51.8 \%$, respectively (Sharkas et al., 2017). Older age, poor differentiation, advanced cancer stage, and right-sided cancers were associated with lower survival rates. A cross-sectional study on $189 \mathrm{CRC}$ patients treated in public and military hospitals in Amman found that the proportion of patients with presentation delay, diagnosis delay or treatment delay was $33.9 \%, 68.1 \%$ and $32.6 \%$, respectively (Abu-Helalah et al., 2016). The main reasons reported for delay in presentation were lack of knowledge that symptoms were suggestive of cancer $(58.5 \%)$, misdiagnosis by physicians or pharmacists $(38.4 \%)$ or the patient did not want to visit a doctor (3.1\%). There is low level of knowledge about CRC signs and symptoms, worryingly combined with an underestimation of risks among Jordanians (Omran et al., 2015; Taha et al., 2015). Thus, this study aims to assess the knowledge and practices of CRC early detection tests and the barriers and motivators of screening in Jordan.

\section{Materials and Methods}

\section{Study setting}

Jordan is a lower middle income country with a population of 9.8 million (2018). In 2017, the average gross domestic product per capita was 4,088 USD. The annual growth rate of the population is $2.4 \%$, and based on that, it is expected that the population will double within 28 years (2018). The life expectancy of women is 74.2 years and that of men is 72.8 . The median age is 22.4 , and the percentage of those aged 65 years and above is $3.7 \%$ of the total population. The illiteracy rate among the population aged 15 years and above is $6.8 \%$; specifically $3.5 \%$ among males and $10 \%$ among females.

\section{Study design}

Stratified clustered random sampling (SCRS) technique was used in this cross sectional study. SCS is a multistage sample design with a margin of error ranging between $2-5 \%$. The clusters were selected from the master sample (census 2004, updated in 2008 and updated in 2012). To ensure the spread of the primary sampling units (PSUs) in the northern, central and southern region, the PSUs within each stratum were arranged according to geographical location. The population frame in Jordan is divided into three stratums, the rural, urban and administrative areas. The sample was distributed proportionally between stratums taking into account the size of each stratum.

\section{Study participants}

Six hundred participants were recruited (300 males and 300 females) from 600 hundred households that were selected from four governorates in Jordan (Amman 370, Zarqa 90, Irbid 100 and Karak 40). The inclusion criteria were healthy Jordanian males or females aged between 30 and 65 years, with no previous history of CRC. The median age was 44 years for females and 43 years for males. Table 1 shows the socio-demographic characteristics of the study participants. Women were significantly less educated than men $(\mathrm{p}=0.001)$ and $78 \%$ of the female participants were housewives. There were insignificant differences between males and females in this study with regards to age distribution, body mass index (BMI) and monthly household income.

\section{Measurement instrument}

A semi-structured questionnaire (SSQ) was developed based on literature review and was validated in forty pilot interviews (20 men and 20 women); ten in each governorate. The SSQ included questions about the socio-demographic characteristics of the participants, their knowledge and perceptions about CRC and their sources of health information; followed by questions to assess the participants' knowledge, practices and attitudes towards CRC early detection tests and their perceived barriers and motivators towards screening (Taha et al., 2015). The CRC knowledge questions were: What is the most common cancer among men in Jordan?; What is the most common cancer among women in Jordan?; Which part of the body is affected by CRC?; What are the risk factors of CRC?; What are the signs and symptoms of CRC? The questions about the participants' screening and practices of early detection examinations for CRC are listed in Tables 3 and 4.

\section{Data collection}

In October 2014, the SSQ was used for data collection in face-to-face interviews. Each interview lasted 40 to 50 minutes. Women were interviewed by female interviewers and men were interviewed by males. Forty eight experienced interviewers and 12 field supervisors collected the data (50\% males and $50 \%$ females). The supervisors guided the data collection in the field, did quality checks on the data and provided assistance. Each team in the field consisted of 4 interviewers and 1 field supervisor, and covered 20 houses per day ( 2 blocks). Each interviewer filled 5 questionnaires on average per day. For quality control, $10 \%$ of the questionnaires were randomly chosen for further phone calls to the respondents. In these phone calls, the respondents were asked a few questions from the questionnaire to double check the answers. For quality assurance, a special data entry software (CsPro) was used to avoid data entry errors.

\section{Ethical issues}

The ethical approval of this study was granted 
from Medical Research Ethical Review Board at the University of Jordan. The participants were informed about the purpose of the study, the voluntary nature of their participation, and their right to access the findings. They had full autonomy to withdraw at any time without giving a reason. Confidentiality of the data was ensured and a verbal consent was sought from all participants.

\section{Statistical methods}

Descriptive and multivariate data analysis was carried out using SPSS 24. The level of statistical significance was set at 0.05 . Descriptive statistics, Chi-square and Fisher's exact tests were used to assess the association between background characteristics with knowledge and practices of CRC early detection examinations. To assess the CRC knowledge (Taha et al., 2015) each correct answer was given a score of one while incorrect or "I do not know" answers were given zero score. Afterwards, the correct answers were grouped into three levels: $0-4,5-8$, and $\geq 9$. Chi-square and Fisher's exact tests were used to assess the association between CRC knowledge scores and the knowledge and practices of CRC early detection tests.

\section{Results}

Previous screening for cancer without having any symptoms

A significantly higher proportion of women $(23 \%$, $\mathrm{n}=70)$ compared to men $(5 \%, \mathrm{n}=15)$ screened for cancer in the absence of symptoms in the last 5 years $(p<0.01)$. Sixty two percent of all the screening tests that women had were for breast cancer, followed by uterine and cervical swabs (20\%), and colon and abdominal general screening (3.6\%). Meanwhile, the majority of screening tests performed by the male participants were prostate $(27 \%)$, bladder $(13 \%)$ and colon $(6.7 \%)$. Table 2 shows the variables that were associated with the participants' screening for cancer during the last 5 years without complaining of any symptoms. There was a direct association between screening practices and sex, occupation, educational level and having a chronic disease $(\mathrm{p}>0.05)$. There were no significant differences in screening practices between the participants according to governorate, age group, monthly income, marital status and body mass index.

\section{Knowledge of CRC early detection tests}

Overall, 24\% of the participants responded that they knew the tests that can be performed to screen for

Table 1. Socio-Demographic Characteristics of the Study Population

\begin{tabular}{|c|c|c|c|c|c|c|c|}
\hline & \multicolumn{2}{|c|}{ Male $(n=300)$} & \multicolumn{2}{|c|}{ Female $(\mathrm{n}=300)$} & \multicolumn{2}{|c|}{ Total $(n=600)$} & P-value \\
\hline Age (year) Mean $\pm \mathrm{SD}$ & \multicolumn{2}{|c|}{$44.6 \pm 10.4$} & \multicolumn{2}{|c|}{$45.1 \pm 9.8$} & \multicolumn{2}{|c|}{$44.1 \pm 10.1$} & 0.575 \\
\hline $\mathrm{BMI}$ mean $\pm \mathrm{SD}$ & \multicolumn{2}{|c|}{$27.5 \pm 5.22$} & \multicolumn{2}{|c|}{$28.22 \pm 5.35$} & \multicolumn{2}{|c|}{$27.83 \pm 5.29$} & 0.075 \\
\hline Age group (years) & $\mathrm{n}$ & $\%$ & $\mathrm{n}$ & $\%$ & $\mathrm{n}$ & $\%$ & \\
\hline $30-40$ & 124 & 41 & 115 & 39 & 239 & 40 & 0.683 \\
\hline $41-50$ & 91 & 30 & 100 & 33 & 191 & 32 & \\
\hline $51-65$ & 85 & 28 & 85 & 28 & 170 & 28 & \\
\hline \multicolumn{8}{|l|}{ Age groups } \\
\hline \multicolumn{8}{|l|}{ BMI Mean \pm SD } \\
\hline $30-40$ years & \multicolumn{2}{|c|}{$27.1 \pm 4.63$} & \multicolumn{2}{|c|}{$26.3 \pm 4.81$} & \multicolumn{2}{|c|}{$26.7 \pm 4.72$} & 0.677 \\
\hline $41-50$ years & \multicolumn{2}{|c|}{$28.3 \pm 6.21$} & \multicolumn{2}{|c|}{$28.6 \pm 5.53$} & \multicolumn{2}{|c|}{$28.5 \pm 5.85$} & 0.259 \\
\hline $51-65$ years & \multicolumn{2}{|c|}{$27.1 \pm 4.79$} & \multicolumn{2}{|c|}{$30.4 \pm 4.92$} & \multicolumn{2}{|c|}{$28.7 \pm 5.11$} & 0.807 \\
\hline Educational level & $\mathrm{n}$ & $\%$ & $\mathrm{n}$ & $\%$ & $\mathrm{n}$ & $\%$ & \\
\hline Below secondary & 100 & 33 & 115 & 39 & 215 & 36 & \\
\hline Secondary & 103 & 34 & 108 & 36 & 211 & 35 & 0.001 \\
\hline College (diploma) & 28 & 9.4 & 43 & 14 & 71 & 12 & \\
\hline University and higher & 69 & 23 & 34 & 11 & 103 & 17 & \\
\hline Monthly household income & $\mathrm{n}$ & $\%$ & $\mathrm{n}$ & $\%$ & $\mathrm{n}$ & $\%$ & \\
\hline Below $500 \mathrm{JD}$ & 212 & 71 & 219 & 73 & 431 & 72 & \\
\hline $500-1,000 \mathrm{JD}$ & 72 & 24 & 76 & 26 & 148 & 25 & 0.132 \\
\hline $1,000-1,500$ & 9 & 3.0 & 4 & 1.3 & 13 & 2.2 & \\
\hline More than 1,500 & 4 & 1.3 & 1 & 0.3 & 5 & 0.8 & \\
\hline Did not answer & 3 & 1.0 & 0 & 0.0 & 3 & 0.5 & \\
\hline Work status & $\mathrm{n}$ & $\%$ & $\mathrm{n}$ & $\%$ & $\mathrm{n}$ & $\%$ & \\
\hline Full time Job & 194 & 65 & 31 & 10 & 225 & 38 & \\
\hline Part time Job & 36 & 12 & 11 & 3.7 & 47 & 7.8 & $<0.001$ \\
\hline Housewife & 0 & 0 & 234 & 78 & 234 & 39 & \\
\hline Unemployed & 70 & 23 & 25 & 8.3 & 95 & 16 & \\
\hline
\end{tabular}


Table 2. Screening for any Cancer During the Last 5 Years without Having Symptoms

\begin{tabular}{|c|c|c|c|c|c|c|c|c|}
\hline & & \multicolumn{2}{|c|}{$\begin{array}{c}\text { Yes } \\
\mathrm{n}=85(14.2 \%)\end{array}$} & \multicolumn{2}{|c|}{$\begin{array}{c}\text { No } \\
\mathrm{n}=495(82.5 \%)\end{array}$} & \multicolumn{2}{|c|}{$\begin{array}{c}\text { Do not remember } \\
n=20(3.3 \%)\end{array}$} & \multirow[b]{2}{*}{$\mathrm{P}$ value } \\
\hline & & $\mathrm{n}$ & $\%$ & $\mathrm{n}$ & $\%$ & $\mathrm{n}$ & $\%$ & \\
\hline \multirow[t]{2}{*}{ Sex } & Male & 15 & 5.0 & 285 & 95 & 0 & 0.0 & $<0.001$ \\
\hline & Female & 70 & 23 & 210 & 70 & 20 & 6.7 & \\
\hline \multirow[t]{3}{*}{ Age groups } & $30-40$ & 24 & 10 & 209 & 87 & 6 & 2.5 & 0.15 \\
\hline & $41-50$ & 32 & 17 & 152 & 80 & 7 & 3.7 & \\
\hline & $51-65$ & 29 & 17 & 134 & 79 & 7 & 4.1 & \\
\hline \multirow[t]{3}{*}{ Marital status } & single & 5 & 9.6 & 46 & 89 & 1 & 1.9 & 0.59 \\
\hline & married & 76 & 15 & 426 & 82 & 17 & 3.3 & \\
\hline & Divorced or widow & 4 & 14 & 23 & 79 & 2 & 6.9 & \\
\hline \multirow[t]{3}{*}{ Monthly income } & Less than 500 JDs & 52 & 12 & 363 & 84 & 16 & 3.7 & 0.17 \\
\hline & $500-1000$ & 30 & 20 & 114 & 77 & 4 & 2.7 & \\
\hline & more than 1,000 & 3 & 14 & 18 & 86 & 0 & 0.0 & \\
\hline \multirow[t]{4}{*}{ Type of occupation } & Works full time & 17 & 7.6 & 206 & 92 & 2 & 0.9 & $<0.001$ \\
\hline & Works part time & 7 & 15 & 39 & 83 & 1 & 2.1 & \\
\hline & Not working & 7 & 7.4 & 84 & 89 & 3 & 3.6 & \\
\hline & Housewife & 54 & 23 & 166 & 71 & 14 & 6.0 & \\
\hline \multirow[t]{4}{*}{ Body mass index } & Underweight $<18.5$ & 2 & 15 & 11 & 85 & 0 & 0.0 & 0.17 \\
\hline & Normal: $18.5-24.9$ & 15 & 9.1 & 147 & 89 & 3 & 1.8 & \\
\hline & Overweight: 25-29.9 & 35 & 17 & 169 & 80 & 8 & 3.8 & \\
\hline & Obese: 30 or more & 29 & 16 & 142 & 79 & 9 & 5.0 & \\
\hline \multirow[t]{4}{*}{ Education level } & Illiterate & 1 & 3.7 & 24 & 89 & 2 & 7.4 & 0.03 \\
\hline & less than high school & 20 & 11 & 165 & 88 & 3 & 1.6 & \\
\hline & high school & 30 & 14 & 169 & 80 & 12 & 5.7 & \\
\hline & College and higher & 34 & 20 & 137 & 79 & 3 & 1.7 & \\
\hline \multirow[t]{2}{*}{ Having a chronic illness } & yes & 28 & 18 & 117 & 76 & 9 & 5.8 & 0.03 \\
\hline & no & 57 & 13 & 378 & 85 & 11 & 2.5 & \\
\hline
\end{tabular}

CRC. Out of the participants that responded as such, $26 \%$ were females and $21 \%$ were males. Knowledge of $\mathrm{CRC}$ early detection tests was associated with having better knowledge of CRC signs and symptoms, having a family history of CRC, knowing someone who had $\mathrm{CRC}$, previously consulting a doctor because of having symptoms and being worried from having $\mathrm{CRC}(\mathrm{p}<0.001)$. Table 3 shows the independent variables that are associated with the participants' perceived knowledge of CRC early detection tests. There was no significant association between knowledge of CRC early detection tests, and age, sex, occupation, educational level or governorate. Of the participants who indicated that they knew the tests, $39 \%$ of them mentioned colonoscopy (females $42 \%$, males $36 \%$ ), 14\% abdominal X-ray, 13\% ultrasound, 12\% FOBT test, $10 \%$ computed tomography virtual colonoscopy, $6 \%$ sigmoidoscopy and 5\% barium enema.

\section{Practices of CRC early detection tests}

Overall, $6.5 \%(\mathrm{n}=39)$ of the participants had previous CRC tests; $2.7 \%$ had FOBT $3.8 \%$ had other CRC tests. There was a significant direct association between previous CRC testing and better knowledge about CRC signs, symptoms and early detection tests $(\mathrm{p}<0.01)$. In Table 4, which shows the association between CRC testing and various variables, participants who had ever consulted a doctor regarding symptoms that they thought might be due to CRC were significantly more likely to have performed FOBT $(\mathrm{p}<0.01)$ or other CRC tests $(p<0.02)$. There was a significant association between the participants' ever having CRC early detection tests and ever having a doctor recommendation to go for CRC testing $(\mathrm{p}<0.001)$. However, there was no significant association between testing for CRC and age, sex, governorate, income, family history and knowing someone who had CRC.

\section{Barriers and motivators of CRC testing}

The majority (61\%) of those aged 50 years and older who did not perform CRC early detection tests said that they did not do so because they did not feel sick, while $4.5 \%$ of them were too afraid to do the test, $4.5 \%$ did not care to do them, $4.5 \%$ did not know enough about the tests and $4.5 \%$ were not instructed by their doctor to do any tests. However, $90 \%$ of those aged 50 years and above indicated that they were willing to participate and have FOBT every one or two years if the government developed national screening programs for CRC and made the FOBT test available for free, while $7 \%$ said that they will not participate and $2.5 \%$ did not know if they 
Table 3. Perceived Knowledge of CRC Early Detection Tests

\begin{tabular}{|c|c|c|c|c|c|c|c|c|}
\hline & & \multicolumn{7}{|c|}{ Do you know which tests are used for diagnosing colon cancer } \\
\hline & & \multirow{2}{*}{\multicolumn{2}{|c|}{$\begin{array}{c}\text { Yes } \\
n=143(24 \%)\end{array}$}} & \multirow{2}{*}{\multicolumn{2}{|c|}{$\begin{array}{c}\text { No } \\
n=423(71 \%)\end{array}$}} & \multirow{2}{*}{\multicolumn{2}{|c|}{$\begin{array}{l}\text { Don't remember } \\
\mathrm{n}=34(5.7 \%)\end{array}$}} & \multirow[b]{3}{*}{ P-value } \\
\hline & & & & & & & & \\
\hline & & $\mathrm{n}$ & $\%$ & $\mathrm{n}$ & $\%$ & $\mathrm{~N}$ & $\%$ & \\
\hline \multirow[t]{2}{*}{ CRC disease knowledge score } & 0 to 4 & 55 & 15 & 287 & 77 & 31 & 8.3 & $<0.001$ \\
\hline & 5 to 13 & 88 & 39 & 136 & 60 & 3.0 & 1.3 & \\
\hline \multirow[t]{2}{*}{ Sex } & Male & 64 & 21 & 219 & 73 & 17 & 5.7 & 0.35 \\
\hline & Female & 79 & 26 & 204 & 68 & 17 & 5.7 & \\
\hline \multicolumn{9}{|c|}{ Do you know anyone who had colon cancer? } \\
\hline & Yes & 38 & 41 & 52 & 56 & 3.0 & 3.2 & $<0.001$ \\
\hline & No & 77 & 27 & 198 & 68 & 15 & 5.2 & \\
\hline & I do not remember & 7 & 13 & 45 & 83 & 2 & 3.7 & \\
\hline & refused to answer & 9 & 23 & 25 & 64 & 5 & 12.8 & \\
\hline \multicolumn{9}{|c|}{ Have you ever had any symptoms that you thought it might be colon cancer? } \\
\hline & Yes & 19 & 61 & 11 & 36 & 1.0 & 3.2 & $<0.001$ \\
\hline & No & 123 & 22 & 410 & 72 & 33 & 5.8 & \\
\hline & I do not remember & 1.0 & 33 & 2.0 & 67 & 0.0 & 0.0 & \\
\hline \multicolumn{9}{|c|}{ Ever consulted a doctor because you were worried that you might have CRC? } \\
\hline & Yes & 12 & 75 & 4 & 25 & 0.0 & 0.0 & $<0.001$ \\
\hline & No & 131 & 22 & 419 & 72 & 34 & 5.8 & \\
\hline \multicolumn{9}{|c|}{ Do you think that you could ever get colon cancer? } \\
\hline & Yes & 34 & 30 & 73 & 65 & 5 & 4.5 & 0.63 \\
\hline & No & 14 & 20 & 53 & 77 & 2 & 2.9 & \\
\hline & With God well No & 85 & 22 & 272 & 71 & 25 & 6.5 & \\
\hline \multicolumn{9}{|c|}{ Did you ever hear, see or read about (FOBT)? } \\
\hline & Yes & 45 & 51 & 41 & 46 & 3 & 3.4 & $<0.001$ \\
\hline & No & 98 & 19 & 379 & 75 & 28 & 5.5 & \\
\hline & I can't remember & 0.0 & 0.0 & 3 & 50 & 3 & 50 & \\
\hline \multicolumn{9}{|c|}{ Did a doctor ever recommended FOBT test for you? } \\
\hline & Yes & 10 & 67 & 4 & 27 & 1 & 6.7 & $<0.001$ \\
\hline & No & 132 & 23 & 419 & 72 & 33 & 5.7 & \\
\hline \multicolumn{9}{|c|}{ Did a doctor ever recommended for you any CRC tests? } \\
\hline & Yes & 17 & 37 & 29 & 63 & 0 & 0.0 & 0.01 \\
\hline & No & 126 & 23 & 389 & 71 & 32 & 5.9 & \\
\hline & I do not remember & 0 & 0.0 & 5 & 71 & 2 & 29 & \\
\hline
\end{tabular}

would. The reasons given by the participants who were not willing to participate in national FOBT screening were: $31 \%$ of them had fear of the results, $24 \%$ unwillingness to participate was due to lack of time, $19 \%$ have no signs and symptoms of cancer, $5 \%$ because their destiny in God hands (fate), and $2 \%$ have no family history.

Of the respondents who indicated that they will participate in FOBT screening programs, 30\% indicated that they will do that to have a peace of mind, $21 \%$ for prevention and early detection, $20 \%$ because of the importance of medical tests, $12 \%$ to know whether they have CRC or not, $11 \%$ to follow doctor's recommendation and $2 \%$ due to family history of colon cancer.

\section{Discussion}

The results of this study showed that both men and women had poor knowledge and practices of CRC early detection tests. Better knowledge and practices were significantly associated with previously consulting a doctor regarding symptoms that they thought might be due to $\mathrm{CRC}$, or being recommended by doctors to do $\mathrm{CRC}$ testing. On one hand, better knowledge of CRC early detection tests was significantly associated with having a family history of CRC or knowing someone who had CRC. On the other hand, there was disappointingly no significant association between CRC early detection practices and having a family history of CRC or knowing someone with CRC.

In our sample, only $24 \%$ of the participants indicated 
Table 4. Practices of CRC Early Detection Tests

\begin{tabular}{|c|c|c|c|c|c|c|c|c|c|c|}
\hline & \multicolumn{4}{|c|}{ Did you ever do FOBT } & \multicolumn{6}{|c|}{ Did you ever do any tests for CRC } \\
\hline & \multicolumn{2}{|c|}{$\begin{array}{c}\text { Yes } \\
n=16(2.7 \%)\end{array}$} & \multicolumn{2}{|c|}{$\begin{array}{c}\text { No } \\
n=584(97 \%)\end{array}$} & \multirow[b]{2}{*}{ P-value } & \multicolumn{2}{|c|}{$\begin{array}{c}\text { Yes } \\
\mathrm{n}=23(3.8 \%)\end{array}$} & \multicolumn{2}{|c|}{$\begin{array}{c}\text { No } \\
n=577(96 \%)\end{array}$} & \multirow[b]{2}{*}{ P-value } \\
\hline & $\mathrm{n}$ & $\%$ & $\mathrm{n}$ & $\%$ & & $\mathrm{n}$ & $\%$ & $\mathrm{n}$ & $\%$ & \\
\hline \multicolumn{11}{|l|}{ Family history of CRC } \\
\hline Yes & 3 & 5.2 & 55 & 95 & 0.31 & 3 & 5.2 & 55 & 95 & 0.45 \\
\hline No & 13 & 3.1 & 405 & 97 & & 17 & 4.1 & 401 & 96 & \\
\hline \multicolumn{11}{|c|}{ Ever consulted a doctor due to symptoms and was worried from CRC } \\
\hline Yes & 3 & 19 & 13 & 81 & 0.01 & 3 & 19 & 13 & 81 & 0.02 \\
\hline No & 13 & 2.2 & 571 & 98 & & 20 & 3.4 & 564 & 97 & \\
\hline \multicolumn{11}{|c|}{ Do you think that you could ever get CRC } \\
\hline Yes & 3 & 2.7 & 109 & 97 & 0.27 & 6 & 5.4 & 106 & 95 & \\
\hline No & 3 & 4.3 & 66 & 96 & & 3 & 4.3 & 66 & 96 & 0.52 \\
\hline God well No & 8 & 2.1 & 374 & 98 & & 11 & 2.9 & 371 & 97 & \\
\hline Don't recall & 2 & 6.1 & 31 & 94 & & 1 & 3.0 & 32 & 97 & \\
\hline \multicolumn{11}{|c|}{ Do you Know the tests used for diagnosing CRC } \\
\hline Yes & 9 & 6.3 & 134 & 94 & 0.01 & 12 & 8.4 & 131 & 92 & \\
\hline No & 6 & 1.4 & 417 & 99 & & 11 & 2.6 & 412 & 97 & 0.01 \\
\hline Don’t & 1 & 2.9 & 33 & 97 & & 0 & 0.0 & 34 & 100 & \\
\hline \multicolumn{11}{|c|}{ Did a doctor ever recommended CRC testing for you } \\
\hline Yes & 12 & 80 & 3 & 20 & 0.00 & 5 & 33 & 10 & 67 & $<0.001$ \\
\hline No & 4 & 0.7 & 580 & 99 & & 18 & 3.1 & 566 & 97 & \\
\hline \multicolumn{11}{|l|}{ Knowledge of CRC } \\
\hline scored $0-4$ & 3 & 0.8 & 370 & 99 & 0.00 & 9 & 2.4 & 364 & 98 & 0.01 \\
\hline scored 5-13 & 13 & 5.7 & 214 & 94 & & 14 & 6.2 & 213 & 94 & \\
\hline
\end{tabular}

that they knew the tests that can be used to check for CRC. Out of these participants, $26 \%$ were females and $21 \%$ were males. The rate of practicing CRC early detection tests was disturbingly low as well (6.5\%). These results are consistent with other studies conducted in Jordan; a previous study about CRC knowledge, attitudes, and practices carried out among a sample of 3196 adults (18 years or older) from all 12 Jordanian governorates showed that only $20 \%$ have heard about at least one of CRC screening tests, and $9.1 \%$ had performed CRC screening tests before (Ahmad et al., 2015). Another cross-sectional study conducted in 2010 aimed to investigate knowledge and beliefs regarding CRC among the Jordanian population by recruiting a sample of 150 participants aged 50 or above from outpatient clinics at two large hospitals in Northern Jordan: it found that only $22 \%$ of the sample had some information about CRC screening. None of participants, however, had previously screened for CRC. The discrepancy between this result and ours may be attributed to the smaller sample size of the other study (Omran and Ismail, 2010). In general, these low rates could be attributed to the lack of national CRC screening programs and awareness campaigns (Ahmad et al., 2015; Abu-Helalah et al., 2016).

The results of our study showed that CRC early detection tests knowledge and practice were associated with previously consulting a doctor due to symptoms raising concerns about $\mathrm{CRC}$, or after receiving a recommendation from a doctor. Interestingly, having a family history of CRC or knowing someone who had CRC were significantly associated with better knowledge of CRC early detection tests, but were not significantly associated with CRC early detection practices. This indicates that the participants do not perceive that they are at risk until they develop symptoms that cause them to worry from colon cancer, as portrayed by $61 \%$ of those who were 50 years of age or older who didn't screen for CRC because they don't feel sick and so believed that they do not need to do any CRC tests. According to the revised health belief model, perceived seriousness and perceived susceptibility of a condition influence the perceived threat and can positively affect screening behaviour. Moreover, the perceived benefits and barriers of a practice can influence health behaviour. Self-efficacy, having cue to action and other modifying sociological variables play an important role as well (Rosenstock, 1990). This is best seen when the participants were asked if they thought that they could ever acquire $\mathrm{CRC}$; 69 of the participants said that they are not susceptible to CRC, and 382 of them said that they will not get it, God willing. Although there was no statistically significant association between low perceived susceptibility and CRC screening uptake, these results reflect the low perceived susceptibility to acquire CRC among the Jordanian population. This is consistent with many studies in Jordan; a study conducted to assess knowledge and perception of CRC in Jordan in a sample of 600 participants aged between 30 to 65 years found that only $19 \%$ of them feel that they might get CRC in their 
lifetime (Taha et al., 2015). Another study found that less than half of the participants perceived themselves as susceptible to have CRC (Omran and Ismail, 2010).

There's a general consensus in the literature regarding the important role of physician recommendations in CRC screening uptake (Beydoun and Beydoun, 2008; Gimeno Garcia, 2012; Koo et al., 2012; Wools et al., 2016). An international study that aimed to study the factors affecting CRC screening in 14 countries in the Asia-Pacific region found that physician recommendations is the most important factor in CRC screening uptake (Beydoun and Beydoun, 2008). Another review article that aimed to investigate the factors that are associated with CRC screening participation mentioned that physician recommendations and awareness of CRC are important predictors of CRC screening participation. According to this paper, physicians and health care workers can disseminate knowledge, decrease perceived barriers, and increase perceived benefits of CRC screening (Gimeno Garcia, 2012).

Other important factors that might affect CRC screening practice, based on the revised health belief model, are the perceived barriers. In our study, commonly reported barriers are not feeling sick, fear, not caring at all, lack of knowledge and lack of physician recommendations. This is congruent with the results of a review article that aimed to study the predictors of CRC screening uptake among those who are 50 years or older in the United States: it was found that that having no symptoms, low perceived susceptibility, fear of the results and lack of physician recommendations were important barriers against CRC screening participation (Beydoun and Beydoun, 2008). Other barriers were reported in the literature, including pain, embarrassment, anxiety and lack of time (Omran and Ismail, 2010; Gimeno Garcia, 2012; Koo et al., 2012).

Our results showed that $90 \%$ of the participants aged 50 years and above indicated that they will participate in a free national screening for CRC if it was developed. According to the literature, it seems that the predictors of the intention to perform CRC screening and the actual screening practice are not the same (Gregory et al., 2011). This could be explained by the role of financial burden and lack of national CRC screening program as barriers towards CRC screening among the Jordanian population. This is consistent with a study conducted in Jordan which showed that the high cost of CRC screening is a major barrier against CRC screening participation (Omran and Ismail, 2010). Another international study found that the existence of a CRC screening program in a country was associated with higher participation rates, while in countries with low and medium participation in CRC screening, the cost was a major barrier, in addition to the absence of screening programs (Koo et al., 2012). The lack of screening program, however, doesn't display the whole story, as 7\% responded that they will not participate in this program, even if it was free. A cross-sectional study with CRC patients at public and military hospitals in Jordan (Abu-Helalah et al., 2016) found that the main predictors of delay in diagnosis and treatment of CRC were lack of knowledge about CRC symptoms (58.5\%), misdiagnosis by physicians or pharmacists $(38.4 \%)$ or the patient did not want to visit a doctor $(3.1 \%)$.

This is in concordance with many studies in the literature, which found that even in regions where there is a well-formed screening program, CRC screening uptake was lower than expected (Beydoun and Beydoun, 2008; Gregory et al., 2011; Gimeno Garcia, 2012; Wools et al., 2016). Thus, it seems that CRC screening uptake is a complex process, depending on many socio-demographic, cultural and psychosocial factors, and not merely health care related factors (Gimeno Garcia et al., 2014).

This study is limited by the sampling method, as the sample was recruited from only four out of twelve governorates in Jordan. However, we think that the use of the SCRS technique in this study made the randomly drawn sample as representative as possible. The main strength of our study is the data collection procedure, which gives participants the freedom to express their views in their own terms, as well as providing statistically reliable, comparable qualitative data. Therefore, we believe that our results are reliable in assessing knowledge and attitudes towards colorectal cancer screening.

In conclusion, our results showed that levels of CRC screening knowledge and practices are low. This indicates the need for raising awareness about CRC early detection tests in Jordan, especially among those aged 50 years and above and those who have a positive family history of the disease, by implementing a national CRC screening program and awareness campaigns. Additionally, physicians should recommend CRC screening for any patient who is at a higher risk of the disease. CRC screening is a complex process, depending on many socio-demographic, cultural, psychosocial and health care related factors. These factors should be studied extensively in future research to aid the application of CRC screening program.

\section{Abbreviations}

CRC: colorectal cancer, ACS: American cancer society, FIT: Fecal Immunochemical Test, FOBT: Fecal Occult Blood Test, BMI: body mass index, PSUs: Primary Sampling Units, SCRS: Stratified Clustered Random Sampling, SSQ: Semi-structured Questionnaire.

\section{Funding}

We thank the King Hussein Cancer Foundation and the University of Jordan for funding this research.

\section{Authors' contributions}

HT and MAJ conceived the study and supervised the data collection and entry. HT conducted the data analysis and drafted the manuscript. MQA participated in the manuscript writing. LA, MAJ and VB critically reviewed the manuscript and the interpretation of the results. All the authors read and approved the final manuscript.

\section{Competing interests}

The authors declare that they have no competing interests.

Asian Pacific Journal of Cancer Prevention, Vol 20 


\section{Acknowledgements}

We acknowledge the surveying team and the management of the centre of strategic studies in the University of Jordan for their efforts in data collection. We also thank the participants for their contribution to this research.

\section{References}

Abu-Helalah MA, Alshraideh HA, Da'na M, et al (2016). Delay in presentation, diagnosis and treatment for colorectal cancer patients in Jordan. J Gastrointest Cancer, 47, 36-46.

ACS (2018). American Cancer Society: Colorectal cancer, early detection, diagnosis, and staging. Accessed on 25 May 2018 https://www.cancer.org/cancer/colon-rectal-cancer/ detection-diagnosis-staging.html.

Ahmad MM, Dardas L, Dardas L, et al (2015). Colorectal cancer in Jordan: prevention and care. Glob Health Promot, 22, 39-47.

Beydoun HA, Beydoun MA (2008). Predictors of colorectal cancer screening behaviors among average-risk older adults in the United States. Cancer Causes Control, 19, 339-59.

Bray F, Ren JS, Masuyer E, et al (2013). Global estimates of cancer prevalence for 27 sites in the adult population in 2008. Int J Cancer, 132, 1133-45.

Ferlay J, Soerjomataram I, Ervik M, et al (2013). GLOBOCAN 2012 v1.0, Cancer Incidence and Mortality Worldwide: IARC Cancer Base No. 11. Lyon, France: International Agency for Research on Cancer, 2013.

Ferlay J, Soerjomataram I, Dikshit R, et al (2015). Cancer incidence and mortality worldwide: sources, methods and major patterns in GLOBOCAN 2012. Int J Cancer, 136, 359-86.

Gimeno Garcia AZ (2012). Factors influencing colorectal cancer screening participation. Gastroenterol Res Pract, 2012, 483417.

Gimeno Garcia AZ, Hernandez Alvarez Buylla N, Nicolas-Perez D, et al (2014). Public awareness of colorectal cancer screening: knowledge, attitudes, and interventions for increasing screening uptake. ISRN Oncol, 2014, 425787.

Gregory TA, Wilson C, Duncan A, et al (2011). Demographic, social cognitive and social ecological predictors of intention and participation in screening for colorectal cancer. $B M C$ Public Health, 11, 38.

Jordan Ministry of Health. National Cancer Registery, 2012 Cancer report. Accessed on 25 May 2018, http://www.moh. gov.jo/Echobusv3.0/SystemAssets/c602eda7-0c36-49cdbea1-3484e46c0b97.pdf.

Koo JH, Leong RW, Ching J, et al (2012). Knowledge of, attitudes toward, and barriers to participation of colorectal cancer screening tests in the Asia-Pacific region: a multicenter study. Gastrointest Endosc, 76, 126-35.

Omran S, Barakat H, Muliira JK, et al (2015). Assessment of Jordanian patient's colorectal cancer awareness and preferences towards CRC screening: Are Jordanians ready to embrace CRC screening?. Asian Pac J Cancer Prev, 16, 4229-35.

Omran S, Ismail AA (2010). Knowledge and beliefs of Jordanians toward colorectal cancer screening. Cancer Nurs, 33, 141-8.

Rosenstock IM (1990). The health belief model: Explaining health behavior through expectancies. In K. Glanz, F. M. Lewis, and B. K. Rimer (Eds.), The Jossey-Bass health series. Health behavior and health education: Theory, research, and practice. San Francisco, CA, US: Jossey-Bass, pp 39-62.
Sharkas GF, Arqoub KH, Khader YS, et al (2017). Colorectal Cancer in Jordan: Survival Rate and Its Related Factors. $J$ Oncol, 2017, 3180762.

Taha H, Jaghbeer MA, Shteiwi M, et al (2015). Knowledge and perceptions about colorectal cancer in Jordan. Asian Pac J Cancer Prev, 16, 8479-86.

Wools A, Dapper EA, de Leeuw JR (2016). Colorectal cancer screening participation: a systematic review. Eur J Public Health, 26, 158-68.

World Bank, Jordan data. Accessed on 25 May 2018.https:// data.worldbank.org/?locations=JO-XN. (2018). Jordan Department of Statistics, Jordan in figures. Accessed on 25 May 2018.http://dosweb.dos.gov.jo/wp-content/ uploads/2017/11/JordanInFigures2016.pdf.

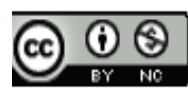

This work is licensed under a Creative Commons AttributionNon Commercial 4.0 International License. 